\title{
The Steroidogenesis Inhibitor Finasteride Reduces the Response to Both Stressful and Rewarding Stimuli
}

\author{
Sean C. Godar ${ }^{1,+}$, Roberto Cadeddu ${ }^{1,+}$, Gabriele Floris ${ }^{1}$, Laura J. Mosher ${ }^{1,2}$, Zhen Mi $^{2}$, \\ David P. Jarmolowicz ${ }^{3,4}$, Simona Scheggi ${ }^{1}$, Alicia A. Walf ${ }^{5,6}$, Carolyn J. Koonce ${ }^{6}$, \\ Cheryl A. Frye ${ }^{6,7,8,9}$, Nancy A. Muma ${ }^{2}$ and Marco Bortolato ${ }^{1, *}$ \\ 1 Department of Pharmacology and Toxicology, College of Pharmacy, University of Utah, Salt Lake, UT 84112, \\ USA; sean.godar@utah.edu (S.C.G.); roberto.cadeddu@utah.edu (R.C.); gabriele.floris@utah.edu (G.F.); \\ laura.mosher@utah.edu (L.J.M.); simona.scheggi@utah.edu (S.S.) \\ 2 Department of Pharmacology and Toxicology, School of Pharmacy; Lawrence, KS 66045, USA; \\ mizhen@ku.edu (Z.M.); nmuma@ku.edu (N.A.M.) \\ 3 Department of Applied Behavioral Science; University of Kansas, Lawrence, KS 66045, USA; dpj@ku.edu \\ 4 Cofrin Logan Center for Addiction Research and Treatment; University of Kansas, Lawrence, KS 66045, USA \\ 5 Department of Cognitive Science, Rensselaer Polytechnic Institute, Troy, NY 12180, USA; walfa@rpi.edu \\ 6 Department of Psychology; The University at Albany-SUNY, Albany, NY 12222, USA; \\ kooncecj@gmail.com (C.J.K.); cafrye@albany.edu (C.A.F.) \\ 7 Department of Biological Sciences; The University at Albany-SUNY, Albany, NY 12222, USA \\ 8 Center for Neuroscience, The University at Albany-SUNY, Albany, NY 12222, USA \\ 9 Comprehensive Neuropsychological Services, Albany, NY 12203, USA \\ * Correspondence: marco.bortolato@utah.edu \\ + These authors contributed equally to this work.
}

Received: 14 October 2019; Accepted: 18 November 2019; Published: 19 November 2019

\begin{abstract}
Finasteride (FIN) is the prototypical inhibitor of steroid $5 \alpha$-reductase $(5 \alpha \mathrm{R})$, the enzyme that catalyzes the rate-limiting step of the conversion of progesterone and testosterone into their main neuroactive metabolites. FIN is clinically approved for the treatment of benign prostatic hyperplasia and male baldness; while often well-tolerated, FIN has also been shown to cause or exacerbate psychological problems in vulnerable subjects. Evidence on the psychological effects of FIN, however, remains controversial, in view of inconsistent clinical reports. Here, we tested the effects of FIN in a battery of tests aimed at capturing complementary aspects of mood regulation and stress reactivity in rats. FIN reduced exploratory, incentive, prosocial, and risk-taking behavior; furthermore, it decreased stress coping, as revealed by increased immobility in the forced-swim test (FST). This last effect was also observed in female and orchiectomized male rats, suggesting that the mechanism of action of FIN does not primarily reflect changes in gonadal steroids. The effects of FIN on FST responses were associated with a dramatic decrease in corticotropin release hormone (CRH) mRNA and adrenocorticotropic hormone (ACTH) levels. These results suggest that FIN impairs stress reactivity and reduces behavioral activation and impulsive behavior by altering the function of the hypothalamus-pituitary-adrenal (HPA) axis.
\end{abstract}

Keywords: $5 \alpha$ reductase; depression; anxiety; impulsivity; finasteride; HPA axis

\section{Introduction}

Steroid $5 \alpha$-reductase $(5 \alpha \mathrm{R})$ is the enzyme catalyzing the saturation of the 4,5 -double bond of the A ring of testosterone, progesterone, and deoxycorticosterone, as well as other ketosteroids [1,2]. The products of this metabolic process, $5 \alpha$-dihydrotestosterone (DHT), $5 \alpha$-dihydroprogesterone (DHP), and $5 \alpha$-dihydrodeoxycorticosterone (DHDOC) are further converted by $3 \alpha$-hydroxysteroid oxidoreductase into $5 \alpha$-androstan-3 $\alpha, 17 \beta$-diol ( $3 \alpha$-diol), tetrahydroprogesterone (allopregnanolone; 
$\mathrm{AP})$, and tetrahydrodeoxycorticosterone (THDOC), respectively. These neuroactive steroids act as positive allosteric modulators of $\mathrm{GABA}_{\mathrm{A}}$ receptors [3,4] and play key roles in the orchestration of reactivity to stress and other environmental stimuli as well as in the pathophysiology of depression and anxiety [5-9]. In addition, $5 \alpha \mathrm{R}$ plays a key role in the degradation of glucocorticoids, such as corticosterone and cortisol, into their $5 \alpha$-reduced metabolites [10].

The prototypical $5 \alpha \mathrm{R}$ inhibitor, finasteride (FIN; N-(2-methyl-2-propyl)-3-oxo-4-aza- $5 \alpha$-androst-1ene-17 $\beta$ carboxamide), was originally approved in the 1990s for the treatment of benign prostatic hyperplasia and male-pattern baldness [2]. These therapeutic actions reflect the best-characterized mechanism of action of FIN, namely the reduction of DHT synthesis in plasma and scalp [11,12]. In addition to this effect, FIN impairs the synthesis of other neuroactive steroids, including AP and $3 \alpha$-diol [13-15]. Although FIN is generally well-tolerated, post-marketing reports of adverse psychological events have led to growing concerns about the safety profile of this drug. Several studies have substantiated that FIN increases the risk for depressive symptoms in a subset of vulnerable patients [16-18]. In addition, several patients have reported that these psychological complications can persist even after FIN discontinuation [18-23], prompting some authors to coin the term "post-finasteride syndrome" (PFS) to define this condition. Altogether, this emerging evidence has led several national agencies to issue warnings about the potential for depression and other psychological sequelae [22,23].

The pathophysiology of PFS and other psychological complications of FIN remain unclear, in view of selection bias in many published clinical studies and high nocebo effect, as well as suboptimal safety information [22,23]. A full characterization of the behavioral effects of FIN is particularly important, given that preliminary reports have indicated that FIN may also have therapeutic properties for several neuropsychiatric conditions characterized by poor impulse control and excessive externalizing manifestations, including Tourette's syndrome and pathological gambling [2,24,25]. Based on this background, the present study tested the behavioral effects of FIN in a broad battery of standardized behavioral tests in rats, in order to assess its effects on complementary aspects of mood regulation, anxiety, impulse control, and stress reactivity. The latter was further characterized by measuring plasma adrenocorticotropin (ACTH) levels and corticotropin-releasing hormone (CRH) mRNA in the paraventricular nucleus (PVN) of the hypothalamus.

\section{Materials and Methods}

\subsection{Animals}

The experiments in this study were performed using Long-Evans rats (Charles River Laboratories, Raleigh, NC, USA) weighing 250-350 g and housed in groups of 3-4 per cage. Unless stated otherwise for specific experimental manipulations, rats were kept with ad libitum access to food and water. For all tests, animals were used only once. Experimental manipulations were carried out in the animals' dark cycle between 10:00 AM and 06:00 PM. All handling and experimental procedures were performed in compliance with the National Institute of Health guidelines and approved by the local Institutional Animal Care and Use Committees. (Protocol 19-05005).

\subsection{Drugs}

FIN was purchased from Carbosynth Limited (Compton, UK) and suspended in a vehicle (VEH) solution containing $5 \%$ DMSO, $5 \%$ Tween 80 , and $90 \%$ sterile saline (SAL; $0.9 \% \mathrm{NaCl}$ ).

\subsection{Orchiectomy}

Gonadectomy and sham surgeries were performed as previously described [26] under aseptic conditions, using a combination of ketamine $(80 \mathrm{mg} / \mathrm{kg}$; Fort Dodge Animal Health, Fort Dodge, IA, USA) and xylazine (10 mg/kg; Bayer Crop. Shawnee Mission, KS, USA) for anesthesia. For both operations, the sac of the scrotum and underlying tunica were incised; orchiectomy was performed by bilateral ligation of the vas deferens and removal of the testes. Incisions were sutured closed. 


\subsection{Locomotor Activity}

Locomotion was tested in a square force plate actometer, as previously described [27]. The apparatus consisted of a white load plate $(42 \times 42 \mathrm{~cm})$ surrounded on all four sides and covered by a clear Plexiglas box ( $30 \mathrm{~cm}$ tall). Four force transducers placed at the corners of each load plate were sampled 100 times/s, yielding a $0.01 \mathrm{~s}$ temporal resolution, a $0.2 \mathrm{~g}$ force resolution, and a $2 \mathrm{~mm}$ spatial resolution. Custom software directed the timing and data-logging processes via a LabMaster interface (Scientific Solutions Inc., Mentor, $\mathrm{OH}, \mathrm{USA}$ ). Total distance traveled was calculated as the sum of the distances between coordinates of the location of center of force, recorded every $0.5 \mathrm{~s}$ over the recording session. Animals were placed in the center and their behavior was monitored for $30 \mathrm{~min}$. The test was performed in complete darkness to avoid potential anxiety-related confounds.

\subsection{Defensive Withdrawal}

Defensive withdrawal test was performed with two alternative variants of our previously described protocol [28]. In the first version, adult rats were placed in a small rectangular black Plexiglas chamber ( $23 \mathrm{~cm}$ height $\times 15 \mathrm{~cm}$ width $\times 25 \mathrm{~cm}$ depth) opened at one end, located $20 \mathrm{~cm}$ from the wall of a cylindrical, stainless-steel, white, open field (124 cm diameter; $56 \mathrm{~cm}$ height), placed under bright light (200 lux), and video-recorded for $15 \mathrm{~min}$. A separate cohort underwent the same procedure, but was initially placed within the open arena, in a position diametrically opposed to the chamber. Behavioral analyses were performed by blinded observers. The latency to leave the chamber and the percentage of time spent in the open field were measured. FIN and its vehicle were administered 45 min before testing.

\subsection{Novelty-Induced Hypophagia}

Rats were single housed and carried within their cage to a dimly illuminated room (50 lux under red light) for four consecutive days. After a $30 \mathrm{~min}$ acclimation period, they were presented with a highly palatable food (two cheese puffs made of corn flour, hydrogenated vegetable fat, cheese powder and salt) [29]. Following this training, a group of animals were transferred to a novel cage $(20 \mathrm{~cm} \times 29 \mathrm{~cm} \times 35.5 \mathrm{~cm}$ ) and moved to a brightly lit room (500 lux, under white light). The other rats were maintained in their home cages under habitual light conditions (50 lux, under red light). Animals in either condition were then treated with either FIN or its vehicle; $45 \mathrm{~min}$ after treatment, they were given two cheese puffs and their behavior was videotaped. The latency to eat and total consumption were recorded by an observer blinded to treatment.

\subsection{Social Interaction}

Social interaction was tested as previously described [30]. Male rats were placed in a novel round aluminum chamber (diameter: $124 \mathrm{~cm}$; height: $56 \mathrm{~cm}$ ) 45 min after treatment with FIN or its vehicle. Social interaction was tested against either foreign counterparts or cage mates. Behavior was videotaped, and the duration of sniffing in the genital, mid-sectional, and facial areas, as well as grooming and rearing behavior, were measured by an observer blinded to treatment.

\subsection{Delay Discounting}

Delay discounting procedure was performed with a modification of previously described protocol [31]. Subjects were 18 male rats, maintained at $85 \%$ of their ad libitum weights by restricting access to food (Teklad Diet 8064, Harlan Laboratories Inc., Indianapolis, IN, USA). Briefly, sessions occurred in eight identical operant conditioning chambers (Med Associates, St. Albans, VT, USA) fitted with two retractable levers, cue lights, a houselight, and a pellet dispenser delivering grain-based pellets ( $45 \mathrm{mg}$; Bio-Serv, Frenchtown, NJ, USA). All experimental events were programmed and recorded using MED-PC IV software. Sessions consisted of 32 trials, divided into four 8 trial blocks. The beginning of a block was signaled by houselight flashing; when each trial began, the houselight 
was continuously illuminated and either one (forced choice trials) or both (free choice trials) levers were inserted into the chamber. Each block consisted of two forced choice trials (during which the rats pressed one of the levers and received the consequence associated with that lever), followed by six free-choice trials between two alternatives: "Smaller-Sooner" (SS), delivering one pellet at 0 s delay, or "Larger-Later" (LL), delivering three pellets at progressively larger delays. Each trial lasted $60 \mathrm{~s}$, inclusive of the response period, the delay (during which levers were retracted), and the intertrial interval (during which levers were retracted). The position of the SS and LL levers was counterbalanced among subjects. For each session, the four blocks of trials differed by the delay on the LL choice, presented in increasing order of delay during each session. Training lasted 30 days and included the following sessions: (1) all trial blocks with $0 \mathrm{~s}$ LL delays; (2) trial blocks with $0 \mathrm{~s}, 1 \mathrm{~s}, 2 \mathrm{~s}$, and $4 \mathrm{~s}$ LL delays; (3) trial blocks with $0 \mathrm{~s}, 1 \mathrm{~s}, 10 \mathrm{~s}, 20 \mathrm{~s}$ LL delays; and (4) trial blocks with $0 \mathrm{~s}, 10 \mathrm{~s}$, $20 \mathrm{~s}, 40 \mathrm{~s}$ LL delays. Rats progressed from each session to the next upon verification of their statistical stability (i.e., no significant differences across three subsequent sessions) Testing with FIN $(25 \mathrm{mg} / \mathrm{kg}$, IP, 45 min before session) or its vehicle was performed under these conditions over 11 sessions.

\subsection{Wire-Beam Bridge Test}

Testing was performed on a methodological variant of our wire-beam bridge protocol [32]. The apparatus consisted of two metal platforms (start and end) raised at $130 \mathrm{~cm}$ from the floor, placed $100 \mathrm{~cm}$ apart, and connected by a horizontal, aluminum wire-beam bridge. The start platform was limited by a wall to limit movements in any other direction. The bridge $(4 \mathrm{~cm}$ wide) consisted of two parallel, $0.1 \mathrm{~cm}$ thick beams, connected perpendicularly by 40 crossties (placed $2.5 \mathrm{~cm}$ apart), and was highly flexible with a downward deflection of $2 \mathrm{~cm}$ per $100 \mathrm{~g}$ load at the center point. Rats were then placed on the start platform, and the latency to cross as well as the number of bridge crossings were recorded. Cut-off test time to cross the bridge was set at $10 \mathrm{~min}$.

\subsection{Forced-Swim Test}

The forced-swim test was performed as previously described [33]. Briefly, rats were tested in clear Plexiglas cylinders $(45.7 \times 30 \mathrm{~cm}$ in diameter) filled with water to $30 \mathrm{~cm}$. The water temperature was maintained at $25^{\circ} \mathrm{C}$. Testing lasted $10 \mathrm{~min}$. Environmental light was kept at 300 lux. Animals were video recorded, and the duration of immobility (s) and the latency to immobility (s) were measured.

\subsection{Saccharin Preference}

Rats were initially tested for baseline saccharin consumption and preference. They were deprived of food and water for $15 \mathrm{~h}$ prior to the test, starting $1 \mathrm{~h}$ before the onset of the dark phase. Each animal was given access to one pre-weighed bottle containing a $0.1 \%$ saccharin solution in tap water. One hour later, the bottle was removed and weighed again, and food and water were placed back in the cage. Saccharin consumption tests were repeated every 3 to 4 days for the following 2 weeks. After stabilization of saccharin consumption, rats were given two bottles, containing a $0.1 \%$ saccharin solution (presented on either the left or the right side of the cage, in counterbalanced order) and water, respectively, for $4 \mathrm{~h}$. Saccharin preference was assessed as the ratio of saccharin solution/total liquid consumed by each rat. After saccharin preference reached stability (assessed by $<10 \%$ variation over three consecutive sessions), rats were assigned to three groups (matching for preference) to be treated with FIN (25-50 mg/kg, IP) or its vehicle. Saccharin solution and water consumption was assessed every $30 \mathrm{~min}$ for $4 \mathrm{~h}$.

\subsection{Quantification of $C R H$ and $A C T H$}

Plasma ACTH levels and CRH mRNA in the PVN were measured to assess hypothalamuspituitary-adrenal (HPA) axis function. Thirty min after FST, rats were decapitated, and brains were rapidly harvested and frozen in liquid nitrogen. Trunk blood was collected into tubes containing $0.5 \mathrm{~mL}$ of $0.3 \mathrm{M}$ EDTA. Plasma aliquots and brains were stored at $-80^{\circ} \mathrm{C}$ until use. ACTH levels were 
determined by radioimmunoassay as previously described [34,35]. Radioactive ${ }^{125}$ I ACTH (specific activity: $2200 \mathrm{Ci} / \mathrm{mmol}$ ) was obtained from Perkin Elmer (Waltham, MA, USA) and DiaSorin (Stillwater, MN, USA), respectively. The intra-assay coefficient of variation was 2.17 for the ACTH assay. The PVN was punched out from $300 \mu \mathrm{m}$ thick sections prepared using a cryostat microtome. Total RNA was isolated using the RNeasy Mini Kit (Qiagen Sciences, Valencia, CA, USA) and preserved in RNAlater ${ }^{\circledR}$ solution (Life Technologies, Carlsbad, CA, USA) according to the manufactures' protocol. First strand cDNA was synthesized using Superscript III Reverse Transcriptase (Life Technologies, Carlsbad, CA, USA). Real-time PCR amplification was performed using 7500 Real-Time PCR System and SYBR green PCR master mix (Life Technologies, Carlsbad, CA, USA). All samples were run in triplicate. The primers were synthesized by Life Technologies (Carlsbad, CA, USA). The forward primer for CRH was CTGATCCGCATGGGTGAAGA and the reverse primer was CAGCAACACGCGGAAAAAGT. The mRNA levels were normalized to TATA-box binding protein (TBP) mRNA. $\Delta C t$ was calculated as the CRH mRNA - TBP mRNA for each sample; $\Delta \Delta \mathrm{Ct}$ was calculated as $\Delta \mathrm{Ct}$ for the experimental condition $-\Delta \mathrm{Ct}$ for the control condition, for $\mathrm{CRH}$.

\subsection{Statistical Analyses}

Normality and homoscedasticity of data were verified by the Kolmogorov-Smirnov test. Parametric and non-parametric statistical analyses of behavioral parameters were performed via one-way ANOVAs or Kruskal-Wallis test. Analyses of delay discounting, saccharin preference, and CRH/ACTH levels were performed via two-way ANOVAs. All post-hoc analyses were performed via Tukey's test. Significance was set at $p<0.05$.

\section{Results}

\subsection{FIN Reduced Exploratory and Appetitive Behavior at Doses That Did Not Affect Locomotor Activity}

The effects of FIN (10, 25, and $50 \mathrm{mg} / \mathrm{kg}$, IP) were first tested on locomotor behavior under complete darkness, to test its effects on intrinsic locomotor activity. FIN did not affect the total distance traveled by rats at any tested dosage (One-way ANOVA, $\mathrm{F}_{3,22}=0.18$, NS; Figure 1A). To characterize the effect of FIN on anxiety-related indices, rats were first tested in defensive withdrawal, a paradigm that captures the propensity of rats to exit a protected small chamber and enter a brightly lit open arena. FIN $(25-50 \mathrm{mg} / \mathrm{kg}$, IP) dose-dependently increased the latency to withdraw from the protected chamber (one-way ANOVA: $\mathrm{F}_{2,35}=9.018, p<0.001$; post-hoc comparisons: VEH vs. FIN 25, $p<0.001$; VEH vs. FIN 50, $p<0.05$, Figure 1B) and the percentage of time spent in the open arena (one-way ANOVA: $\mathrm{F}_{2,35}=15.71, p<0.001$; post-hoc comparisons: VEH vs. both FIN 25 and FIN 50: $p$ 's < 0.001; Figure 1C).

A

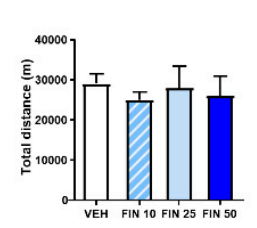

B

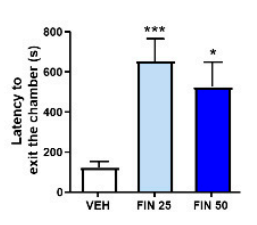

Rat in chamber
C

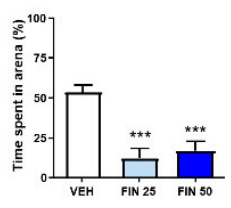

D

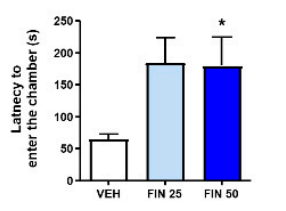

Rat in arena

E

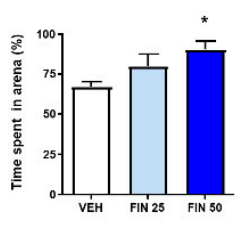

\section{西}

Figure 1. Finasteride (FIN) reduced exploratory drive in the defensive withdrawal paradigm. FIN did not affect locomotor activity in rats tested in an actometer under total darkness; $n=6-7 /$ group (A). In the defensive withdrawal paradigm, FIN increased the latency to exit from a protected chamber and enter a brightly lit open arena (B), as well as the percentage of time spent in the arena itself, $n=12 /$ group (C). However, when animals were first placed in the open arena, FIN increased the latency to enter the protected chamber (D) and prolonged the percentage of time spent in the open arena $n=8 /$ group (E). ${ }^{*} p<0.05,{ }^{* * *} p<0.001$ in comparison with rats treated with vehicle $(\mathrm{VEH})$. Doses of finasteride are indicated in $\mathrm{mg} / \mathrm{kg}(\mathrm{IP})$. 
A reduced proclivity to exit the enclosed chamber may signify either an increased anxiety-like response or a reduced exploratory drive; thus, to tease out the meaning of the observed behavioral effects of FIN, we repeated the same test with a second cohort of rats, which were initially placed in the open arena. In this version of the paradigm, FIN $(50 \mathrm{mg} / \mathrm{kg}$, IP) increased the latency to enter the protected chamber (one-way ANOVA: $\mathrm{F}_{2,21}=4.35, p<0.05$; post-hoc comparisons: VEH vs. FIN 50, $p<0.05$; Figure 1D) and prolonged the percentage of the time spent in the open arena (one-way ANOVA: $\mathrm{F}_{2,21}=4.70, p<0.05$; post-hoc comparisons: VEH vs. FIN 50, $p<0.05$; Figure 1E). These results suggest that FIN reduced behavioral activation irrespective of the anxiogenic characteristics of the environment.

We then tested the effects of FIN in the novelty-induced hypophagia test. FIN-treated rats displayed an increased latency to consume palatable food in a novel cage (Kruskal-Wallis, $\mathrm{H}_{2}=6.65$, $p<0.05$; post-hoc comparisons: VEH vs. FIN 50, $p<0.05$; Figure 2A) and decreased the amount of food consumed (One-way ANOVA; $F_{2,28}=6.98, p<0.01$; post-hoc comparisons: VEH vs. FIN 50, $p<0.01$; Figure 2B). To verify whether the greater food avoidance induced by FIN reflected an actual increase in contextual neophobia, rather than a generalized reduction in appetitive drive, we used a separate cohort of rats to test whether FIN also reduced the consumption of the same palatable food in the home cage. Notably, FIN-treated rats exhibited a marked increase in the latency to consume food (one-way ANOVA; $\mathrm{F}_{2,24}=3.66, p<0.05$; post-hoc comparisons: VEH vs. FIN 25, $p<0.05$; Figure $2 \mathrm{C}$ ) and reduce the amount of food consumed (one-way ANOVA; $\mathrm{F}_{2,24}=13.36, p<0.001$; post-hoc comparisons: VEH vs. FIN 25 and 50, $p^{\prime} \mathbf{s}<0.001$; Figure 2D), again supporting the conclusion that FIN reduces incentive motivation towards rewarding stimuli, rather than increasing anxiety.

A

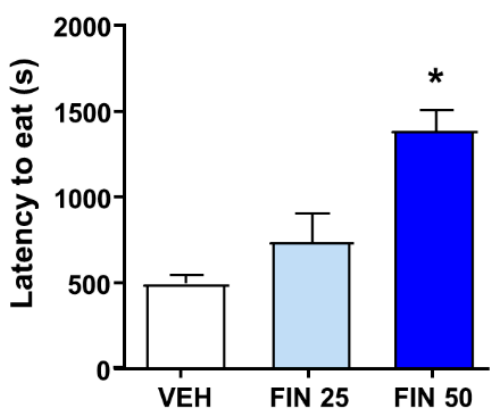

C

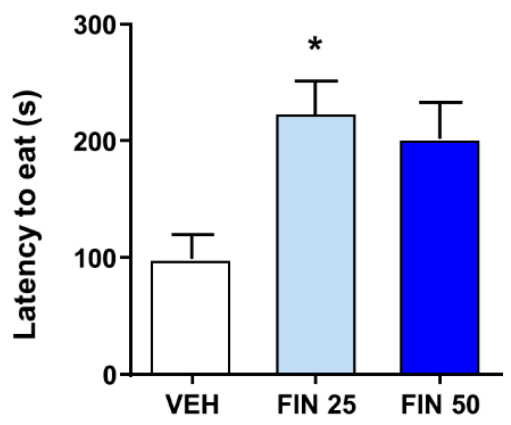

B

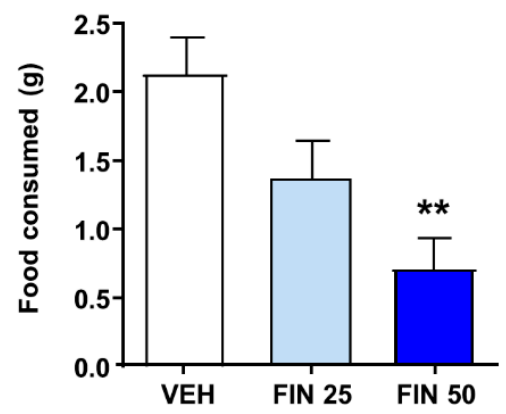

D

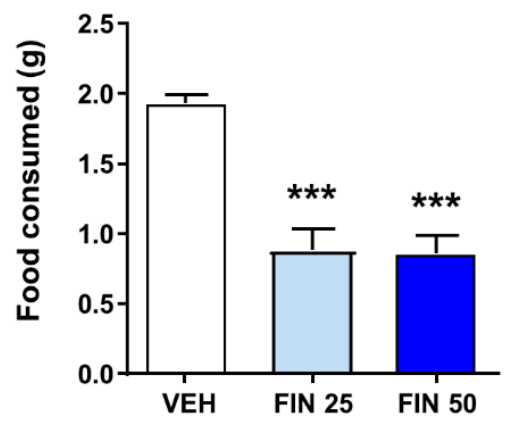

Figure 2. Finasteride (FIN) reduced appetitive motivation in the novelty-induced hypophagia test. In a novel cage, FIN-treated rats displayed an increased latency to consume palatable food (A) and reduced amounts of food consumed (B); $n=10-11$ /group. Similar outcomes, however, were also observed in home cages; $n=9 /$ group $(\mathbf{C}, \mathbf{D}) .{ }^{*} p<0.05,{ }^{* *} p<0.01,{ }^{* * *} p<0.001$ in comparison with rats treated with vehicle (VEH). Doses of FIN are indicated in $\mathrm{mg} / \mathrm{kg}$ (IP). 


\subsection{FIN Reduced Sociability in Rats}

The effects of FIN on social interaction with foreign rats were examined to verify the impact of this drug on social anxiety. FIN significantly reduced the duration of genital (one-way ANOVA, $\mathrm{F}_{2,25}=9.31, p<0.001$; post-hoc comparisons: VEH vs. FIN 25 and 50, $p<0.01$; Figure 3A), mid-section (one-way ANOVA, $\mathrm{F}_{2,25}=46.39, p<0.001$; post-hoc comparisons: VEH vs. FIN 25 and 50, $p<0.001$; Figure $3 \mathrm{~B}$ ), and facial sniffing (one-way ANOVA, $\mathrm{F}_{2,25}=6.49, p<0.01$; post-hoc comparisons: VEH vs. FIN 25, $p<0.01$; VEH vs. FIN 50, $p<0.05$; Figure 3C); however, FIN did not affect the latency to the first social approach (one-way ANOVA, $\mathrm{F}_{2,25}=1.95$, NS; Figure 3D). FIN also reduced rearing (one-way ANOVA, $\mathrm{F}_{2,25}=8.28, p<0.01$; post-hoc comparisons: VEH vs. FIN 25 and 50, $p<0.01$; Figure 3E), but not grooming behavior (one-way ANOVA, $\mathrm{F}_{2,25}=0.38$, NS; Figure $3 \mathrm{~F}$ ).

A
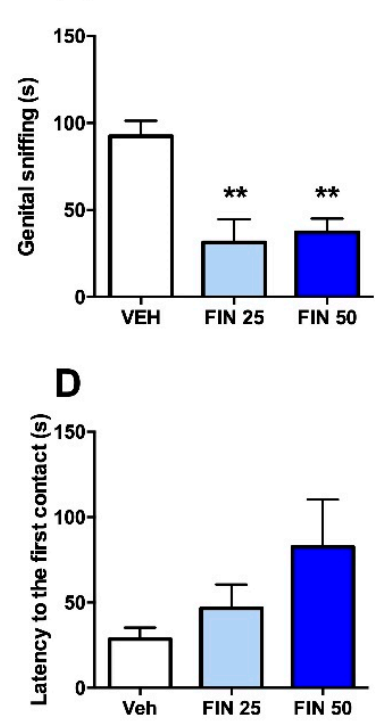

B

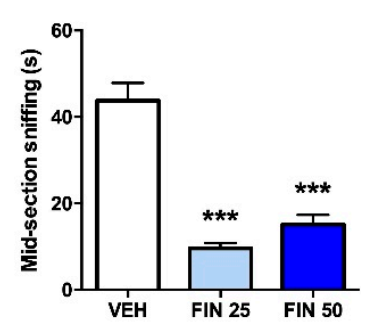

E

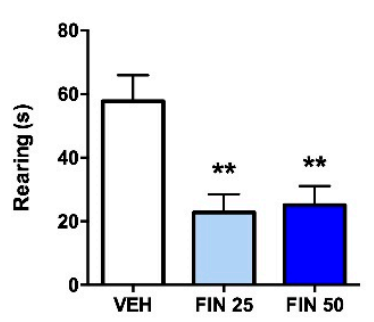

C

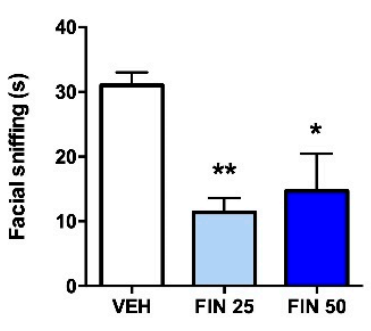

$\mathbf{F}$

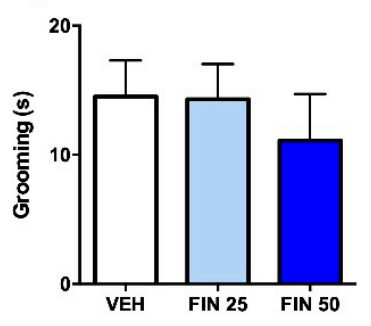

Figure 3. Finasteride (FIN) reduced social interaction with foreign social counterparts. When encountering foreign rats, FIN-treated rats exhibited significant reductions in the duration of genital (A), mid-section (B), and facial sniffing (C), but no changes in the latency to the first social approach, $n=9 / 10 /$ group (D). In addition, FIN reduced rearing (E), but not grooming responses $(\mathbf{F}) .{ }^{*} p<0.05,{ }^{* *} p<0.01, * * * p<0.001$ in comparison to rats treated with vehicle (VEH). Doses of FIN are indicated in $\mathrm{mg} / \mathrm{kg}$ (IP).

To understand whether the social avoidance observed in FIN-treated rats was related to social anxiety or to a reduction of prosocial drive, we tested the effects of FIN on social interaction with familiar rats (weight-matched cage mates).

In this version of the test, both doses of FIN elicited a significant reduction of genital sniffing (one-way ANOVA, $\mathrm{F}_{2,20}=6.58, p<0.01$; post-hoc comparisons: VEH vs. FIN 25 and 50, $p<0.05$, Figure $4 \mathrm{~A}$ ). Furthermore, the $25 \mathrm{mg} / \mathrm{kg}$ dose of FIN reduced mid-section sniffing (one-way ANOVA, $\mathrm{F}_{2,20}=5.98, p<0.01$; post-hoc comparisons: VEH vs. FIN 25, $p<0.01$; Figure 4B). None of the other behavioral parameters, however, were affected by FIN, irrespective of the dose (facial sniffing: one-way ANOVA, $\mathrm{F}_{2,20}=1.19$, NS; latency to the first contact: one-way ANOVA, $\mathrm{F}_{2,20}=3.29$, NS; rearing: one-way ANOVA, $\mathrm{F}_{2,20}=0.086$, NS; grooming: one-way ANOVA, $\mathrm{F}_{2,20}=0.627$, NS). 

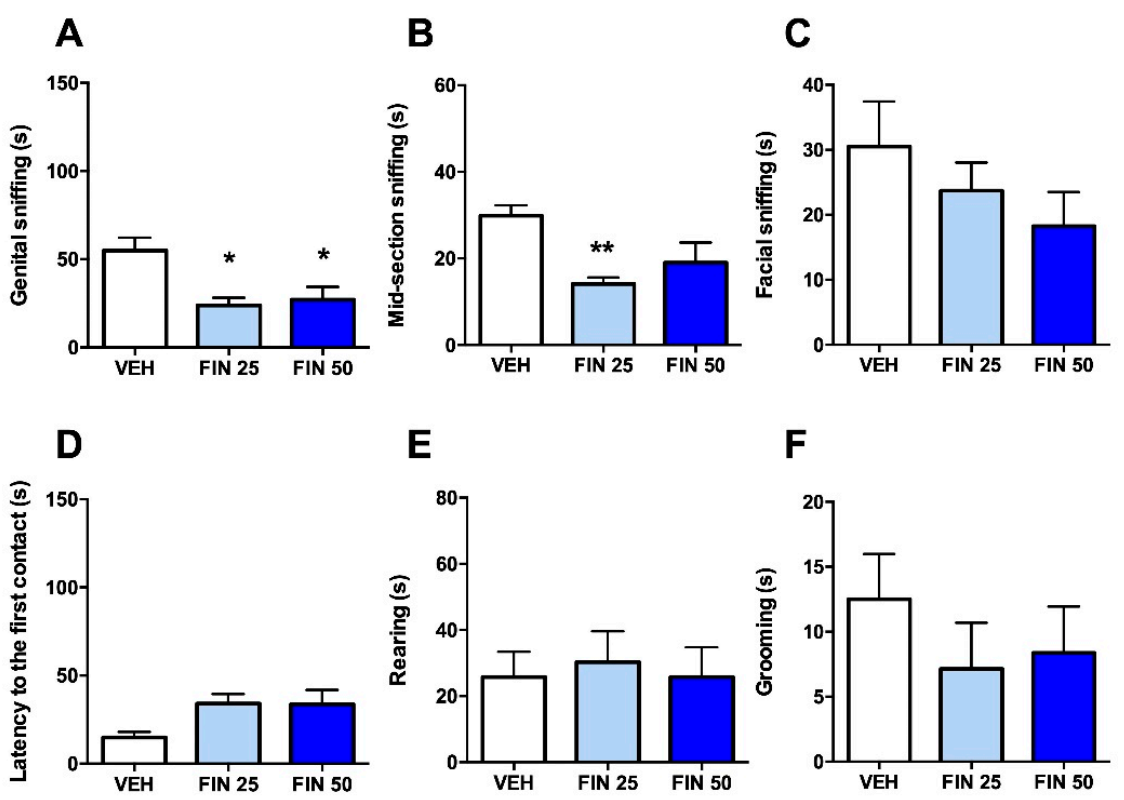

Figure 4. Finasteride (FIN) reduced social interaction with familiar social counterparts. FIN decreased the duration of the exploration of genital area (A) and mid-section (B), but not facial areas (C) of cage mates. Furthermore, FIN had no effect on the latency to the first social approach (D), duration of rearing behavior $(\mathbf{E})$ and grooming; $n=7-8 /$ group $(\mathbf{F}) .{ }^{*} p<0.05,{ }^{* *} p<0.01$ in comparison with rats treated with vehicle (VEH). Doses of FIN are indicated in $\mathrm{mg} / \mathrm{kg}$ (IP).

\subsection{FIN Reduced Impulsivity and Risk-Taking Responses}

We next tested whether FIN affected risk taking and other facets of impulsivity. In a delay-discounting paradigm, two-way ANOVA analyses of \%LL responses revealed an interaction between FIN and delay $\left(\mathrm{F}_{3,80}=4.24, p<0.05\right)$. Post-hoc analyses revealed that FIN induced a shift toward SS reward choices in correspondence of longer delays (20 and $40 s)\left(p^{\prime} \mathrm{s}<0.05\right.$; Figure $\left.5 \mathrm{~A}\right)$, signifying a reduction in delay discounting. No omissions of lever presses were observed in any experimental group. FIN also reduced risk-taking behavior in the suspended wire-beam bridge paradigm, as signified by a longer latency to cross the bridge (one-way ANOVA, $\mathrm{F}_{2,27}=7.90, p<0.01 ; p<0.05$ and $p<0.01$ for comparisons between $25 \mathrm{mg} / \mathrm{kg}$ and $50 \mathrm{mg} / \mathrm{kg}$ FIN, respectively: Figure 5B), as well as a reduced distance traveled on the apparatus (one-way ANOVA, $\mathrm{F}_{2,27}=17.02, p<0.001$; $p<0.05$ and $p<0.01$; for comparisons between $25 \mathrm{mg} / \mathrm{kg}$ and $50 \mathrm{mg} / \mathrm{kg}$ FIN, respectively; Figure $5 \mathrm{C}$ ).

A

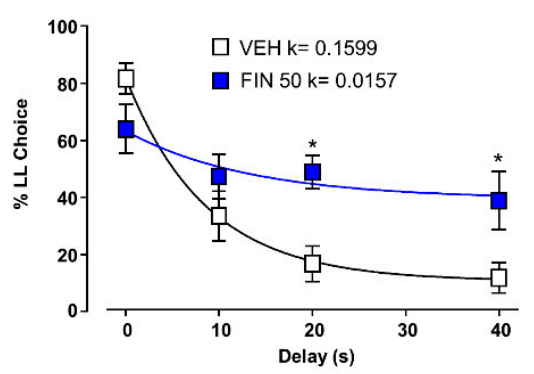

B

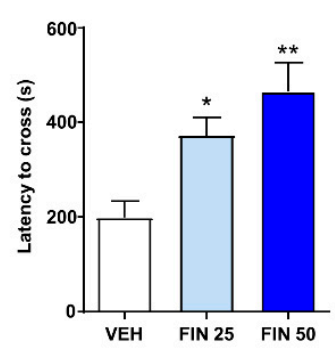

C

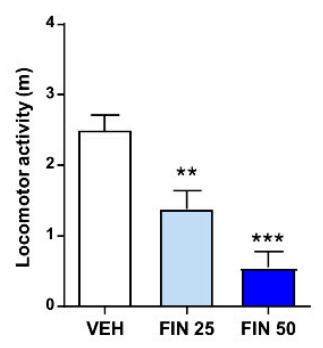

Figure 5. Finasteride (FIN) decreased impulsive and risk-taking responses. In the delay-discounting paradigm (A), FIN decreased the discounting rate corresponding to longer delays (20 and $40 \mathrm{~s}$ ); $n=11-12$ /group. In the wire-beam bridge, FIN-treated rats showed longer latency to cross the bridge (B) and an overall reduction in the distance traveled on the apparatus (C); $n=10 /$ group (C). $p<0.05$, ** $p 0.01,{ }^{* * *} p<0.001$ in comparison with rats treated with vehicle (VEH). Doses of FIN are indicated in $\mathrm{mg} / \mathrm{kg}(\mathrm{IP})$. 


\subsection{FIN Reduced Saccharin Preference}

We then determined whether FIN affected the preference for rewarding stimuli. To this end, the influence of FIN on behavioral reactivity to a sweet solution was assessed by measuring the preference for a saccharin $(0.1 \%)$ solution. Two-way, repeated-measure ANOVA showed a significant effect of the treatment $\left(\mathrm{F}_{2,28}=5.120, p<0.05\right)$ and time $\left(\mathrm{F}_{7,196}=3.24, p<0.01\right)$, as well as their interaction $\left(\mathrm{F}_{14,196}=1.73, p=0.05\right)$. A deficit in the expression of saccharin preference was observed in rats treated with $50 \mathrm{mg} / \mathrm{kg}$ FIN between 180 and $240 \mathrm{~min}$ after treatment $\left(p^{\prime} \mathrm{s}<0.05\right.$; Figure $\left.6 \mathrm{~A}\right)$. Conversely, the $25 \mathrm{mg} / \mathrm{kg}$ dose did not significantly affect saccharin preference. No significant effects of FIN were observed in the total liquid consumption (treatment: $\mathrm{F}_{2,28}=2.65$, NS; time $\times$ treatment interaction: $\mathrm{F}_{14,196}=0.98, \mathrm{NS}$; Figure $\left.6 \mathrm{~B}\right)$.
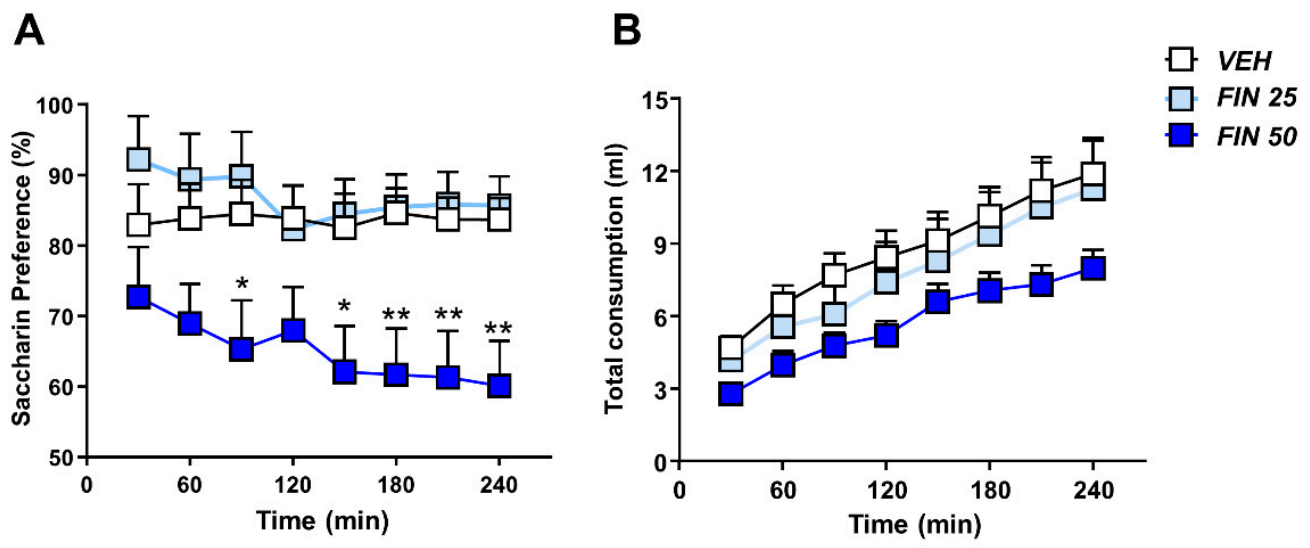

Figure 6. Finasteride reduced saccharin preference. The $50 \mathrm{mg} / \mathrm{kg}$ dose of FIN reduced saccharin preference in the saccharin preference test (A) without modifying total liquid consumption (B); $n=10-11 /$ group; ${ }^{*} p<0.05,{ }^{* *} p<0.01$ in comparison with rats treated with vehicle (VEH). Doses of FIN are indicated in $\mathrm{mg} / \mathrm{kg}$ (IP).

\subsection{FIN Reduced Stress Coping Behavior and Suppressed HPA Axis Responses}

Finally, we investigated the effects of FIN on acute stress coping. To this end, the effects of different doses of FIN $(10,25$, and $50 \mathrm{mg} / \mathrm{kg}$, IP) were evaluated in the FST. In males, FIN treatment significantly affected both the duration of immobility (one-way ANOVA; $\mathrm{F}_{3,40}=6.67, p<0.001$; Figure 7A) and the latency to immobility (one-way ANOVA, $\mathrm{F}_{3,40}=6.28, p<0.01$; Figure 7B). Post-hoc analysis revealed that FIN 25 and $50 \mathrm{mg} / \mathrm{kg}$ increased total immobility $(p<0.05$ and $p<0.001$ compared to VEH, respectively; Figure 7A) and decreased the latency to immobility ( $p<0.05$ and $p<0.01$ compared to VEH, respectively; Figure 7B). To examine whether the effects of FIN on the FST could be reflective of changes in peripheral levels of testosterone and its derivatives, we then tested the effects of this drug in male orchiectomized and female rats. In females, FIN 50 increased total immobility (Student's $t$-test, $p<0.05$; Figure 7C), although it did not significantly affect the latency to immobility (Figure 7D). The analysis of the effects of FIN on castrated males revealed that both orchiectomy (two-way ANOVA: $\mathrm{F}_{1,36}=5.139, p<0.05$; main effect of orchiectomy) and FIN (50 mg/kg, IP) $\left(\mathrm{F}_{1,36}=12.46, p<0.001\right)$ significantly increased immobility; however, no interaction between these factors was detected $\left(F_{1,36}=2.16, N S\right)$, indicating that the depressogenic effects of FIN were not modified by the removal of gonads.

To further understand the mechanisms underlying the effects of FIN $(50 \mathrm{mg} / \mathrm{kg}$, IP) on the stress response, we tested the impact of this drug on CRH transcript levels in the PVN, as well as ACTH plasma concentrations at $30 \mathrm{~min}$ after FST. Two-way ANOVA analyses showed that, in line with previous results [36], CRH mRNA was increased by stress exposure (main effect of stress: $\mathrm{F}_{1,10}=112.8, p<0.001$ ) and decreased by FIN (main effect of treatment: $F_{1,10}=69.51, p<0.001$ ). Furthermore, a significant treatment $\times$ stress interaction was found $\left(\mathrm{F}_{1,10}=75.85, p<0.001\right)$. Post-hoc comparisons revealed that FIN drastically reduced CRH mRNA levels in both stressed and unstressed rats ( $p^{\prime} \mathrm{s}<0.001$; Figure 8A). 
Furthermore, no differences in CRH transcript were found between FIN-treated rats, irrespective of their exposure to FST. The analysis of ACTH plasma levels showed a significant main effect of FIN $\left(\mathrm{F}_{1,34}=70.68, p<0.001\right)$ and FIN $\times$ stress interaction $\left(\mathrm{F}_{1,34}=7.56, p<0.01\right)$. Post-hoc comparisons showed that, as previously described, FST stress increased ACTH plasma levels [37] in both FINand vehicle-treated rats (VEH/no stress vs. VEH/stress, $p<0.001 ;$ FIN 50/no stress vs. FIN 50/stress, $p<0.01$ ); however, FIN blunted the ACTH response in the stressed rats (VEH/stress vs. FIN 50/stress, $p<0.05$; Figure $8 \mathrm{~B})$.

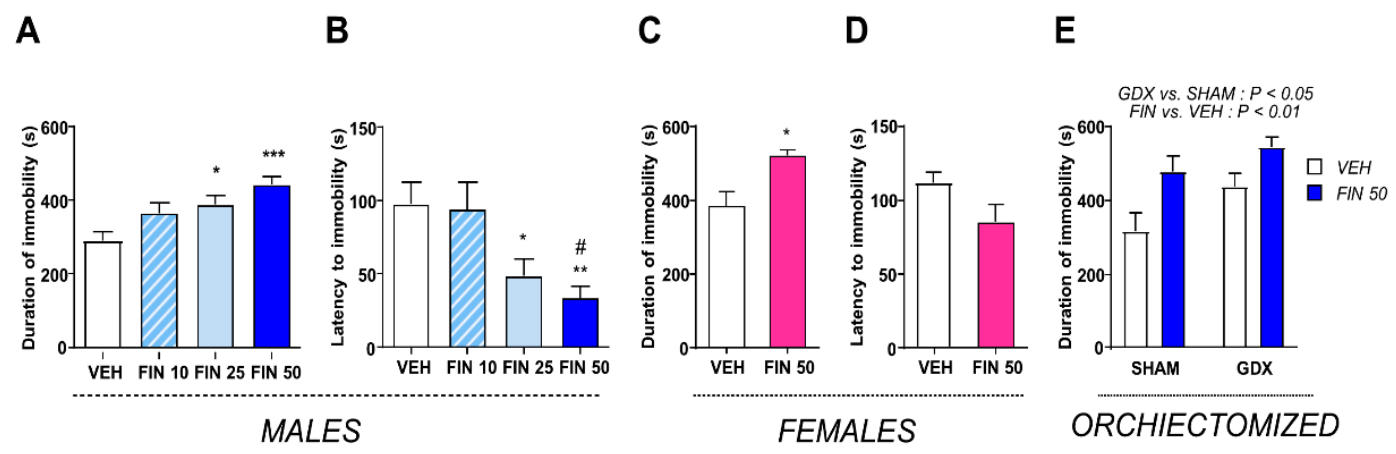

Figure 7. Finasteride (FIN) reduced stress coping behavior in the forced-swim test. In male rats, FIN increased the duration of immobility (A) and reduced the latency to immobility (B); $n=12 /$ group. In female rats, FIN affected only the duration of immobility (C), but not the latency (D); $n=8-9 /$ group. The depressogenic effect was not modified by gonadectomy (E); $n=9-11 /$ group (GDX) (E). ${ }^{*} p<0.05$, ${ }^{* *} p 0.01,{ }^{* * *} p<0.001$ in comparison with rats treated with vehicle (VEH); $\# p<0.05$ in comparison with FIN (10 mg/kg, IP). Doses of FIN are indicated in $\mathrm{mg} / \mathrm{kg}$ (IP).

A

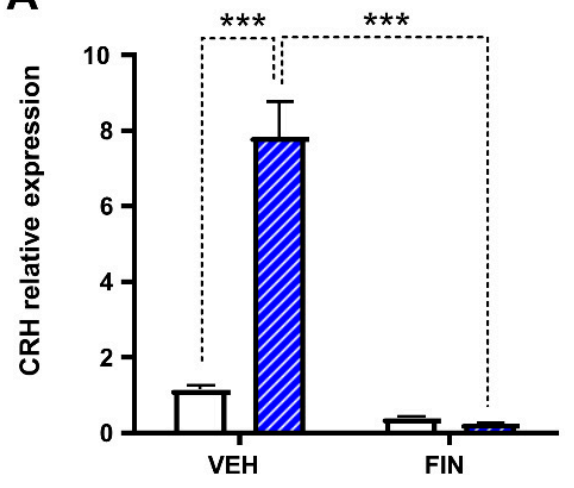

B

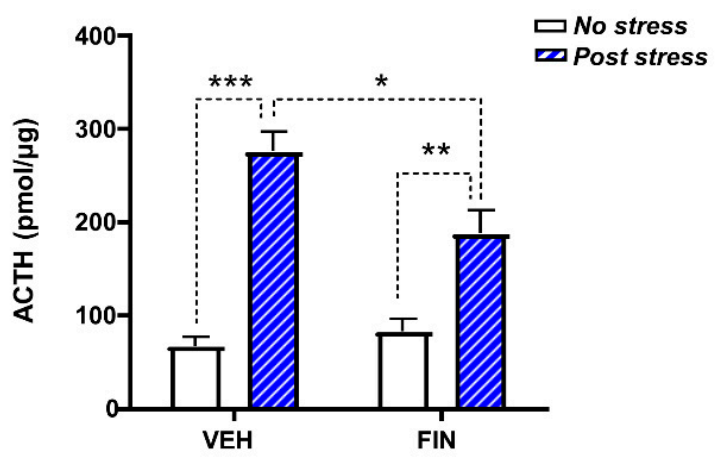

Figure 8. Finasteride (FIN, $50 \mathrm{mg} / \mathrm{kg}$, IP) suppressed hypothalamus-pituitary-adrenal (HPA) axis responsiveness. (A) FIN completely suppressed the levels of transcript of corticotropin releasing hormone $(\mathrm{CRH})$ in the paraventricular nucleus $(\mathrm{PVN})$ of the hypothalamus, in rats subjected to forced-swim stress or non-stressful conditions ( $n=4$ /group). (B) FIN also reduced plasma ACTH levels in stressed rats $\left(n=9-10 /\right.$ group). ${ }^{*} p<0.05,{ }^{* *} p 0.01,{ }^{* * *} p<0.001$ for all comparisons indicated by dotted lines.

\section{Discussion}

The results of this study showed that, in Long-Evans rats, doses of FIN that did not intrinsically reduce locomotor activity attenuated the behavioral responses to a wide array of environmental stimuli, ranging from incentive and rewarding to stressful and aversive. The effects of FIN were first tested in a battery of conflict-based paradigms, including defensive withdrawal, novelty-induced hypophagia, and social interaction. These tests were aimed at measuring complementary facets of anxiety-like behavior as a function of the contrast between the rats' innate avoidance of potentially threatening cues (including brightly lit or novel contexts and unfamiliar rats) and their propensity to 
engage in diversive exploration or consume palatable food. Under these experimental settings, FIN reduced the proclivity to transition from a brightly lit arena to a protected chamber, attenuated the motivation to eat cheese puffs in a novel cage, and decreased the overall duration of social investigation of foreign rats. To verify whether these responses reflected an actual enhancement of anxiety, the effects of FIN were re-tested in alternative versions of the same testing procedures, specifically designed to assess how behavioral reactivity could be modified by abating the ethological conflict between approach and avoidance. Our results showed that the avoidance-enhancing properties of FIN were not substantially modified by these conditions, suggesting that the primary effect of FIN was based on the reduction of goal-driven behaviors and arousal associated with salient stimuli, irrespective of the anxiogenic properties of the context and cues. In keeping with this interpretation, FIN reduced saccharin preference, a well-characterized index to measure reward sensitivity [38], but did not affect self-grooming, a behavior associated with anxiety and psychological burden secondary to stress [39]. In addition, FIN suppressed sensation-seeking and risk-taking behaviors in the delay discounting and wire-beam bridge paradigms. These results were reminiscent of preliminary clinical evidence pointing to a potential therapeutic effect of FIN in neuropsychiatric disorders featuring high impulsivity, such as problem gambling [25] and Tourette's syndrome [24,40].

We also found that FIN increased the duration of the FST immobility, a behavioral parameter that measures of stress coping abilities in rodents [41]. Together with the reduction in saccharin or sucrose preference, this index has been long regarded as one of the most robust predictors of depression-like responses in animal models [42]. From this perspective, our findings were consistent with clinical reports indicating the association of FIN with depressive symptoms, including behavioral apathy and anhedonia [43]. Our experiments revealed that FIN yielded similar effects on stress reactivity in both sexes as well as in castrated males. Although FIN is only approved for clinical use in male patients, FIN is often used in women as a treatment for hirsutism, hair loss, and other hyperandrogenic conditions [44-47]. Thus, caution should be exercised in recommending FIN therapy in women with a well-known predisposition to depression and other psychological problems. Furthermore, our finding that FIN compounded the reduction of stress coping in orchiectomized male rats suggests that, in hypogonadic men, FIN might exacerbate their depressive symptoms, one of the most common manifestations observed in this patient group [48].

These findings also suggest that the depressogenic effects of FIN are likely not directly dependent on variations in peripheral sex hormones, but rather reflect the role of neural mechanisms. In agreement with this concept, we showed that FIN reversed the activation of the HPA axis (signified by the enhancement of CRH transcript and ACTH plasma levels) in response to acute FST stress. Several neurochemical processes may account for this effect. First, FIN blocks the synthesis of THDOC and other $5 \alpha$-reduced neurosteroids, which promote CRH synthesis by activating GABAergic neurons in the PVN $[49,50]$. Second, FIN increases levels of progesterone, which has been described to exert negative effects on CRH synthesis in the PVN [51]. Third, by interfering with corticosterone degradation, FIN may enhance the levels of this hormone and potentiate its effects on the negative feedback regulation of $\mathrm{CRH}$ and ACTH synthesis [52,53].

Although our experiments did not directly assess a causal nexus between the variations in CRH and ACTH and FIN-associated behavioral changes, this link is in line with the key role of CRH in the promotion of physiological and behavioral responses to stress [54,55]. In particular, the idea that an acute reduction in CRH and ACTH levels may result in increased FST immobility has been indirectly supported by previous reports denoting the negative effects of these hormones on this behavioral response [56,57]. It is also worth noting that, in addition to its effects on stress response, CRH enables arousal and behavioral activation, irrespective of stress [58-60].

In addition to the reduction in HPA axis hormones, other mechanisms may be involved in the effects of FIN. For example, the effects of this drug on the reduction of responses to salient stimuli may reflect the marked antidopaminergic effects of FIN in the prefrontal cortex and nucleus accumbens, which have been documented by our previous studies [26,61-63]; indeed, dopaminergic signaling in 
these brain areas is pivotal to allowing for behavioral arousal and salience appraisal $[64,65]$. Future studies are needed to understand the involvement of the HPA axis, dopamine pathways, or other neural mechanisms in the behavioral effects of FIN.

In contrast with our findings, a recent report showed that subchronic, but not acute FIN increased forced-swim immobility in Wistar rats [66]. A possible explanation for these discrepancies might depend on specific variations in testing protocols or genetic background of rats, given the different effects of FIN across different rat strains [62]. Several limitations of our study should be acknowledged. First, our experiments did not qualify the specific $5 \alpha \mathrm{R}$ isoform responsible for the effects of FIN. In humans, FIN has been shown to act as a potent inhibitor of $5 \alpha \mathrm{R}$ type $2\left(5 \alpha \mathrm{R} 2 ; \mathrm{IC}_{50}\right.$ : $\left.69 \mathrm{nM}\right)$, while it inhibits type $1(5 \alpha \mathrm{R} 1)$ less effectively $\left(\mathrm{IC}_{50}: 360 \mathrm{nM}\right)$ [67]. However, in rats, FIN acts as a potent inhibitor of both $5 \alpha \mathrm{R} 1$ and $5 \alpha \mathrm{R} 2$ due to a tetrapeptide sequence encoded by the exon 1 of the rat gene that confers sensitivity to $5 \alpha \mathrm{R} 1$ [68]. Although these two isoenzymes serve similar catalytic functions, they differ by intracellular and anatomical distribution [69-71]. In the CNS, while $5 \alpha \mathrm{R} 1$ immunoreactivity is present in both neurons and glia, the distribution of $5 \alpha \mathrm{R} 2$ is limited to some neurons (such as the pyramidal cells of the cortex) [69,72]. Thus, it is possible that some of our findings may not be fully translatable into complications observed in humans. Irrespective of these issues, the possibility that $5 \alpha \mathrm{R}$ inactivation may be associated with depression-related outcomes is consistent with our previous studies documenting that chronic psychosocial stress leads to the downregulation of both isoforms [73].

Second, most effects reported in this study were limited only to the acute effects of FIN. Nevertheless, the increase in FST immobility reported in this study was similar to the effects of other regimen of FIN administration, including sub-chronic administration and after prolonged discontinuation of the drug $[66,74]$. Further investigations are warranted to verify whether the impairments in stress caused by these different regimens are underpinned by similar neurobiological processes.

Finally, our studies did not qualify which changes in steroid profiles are responsible for the behavioral effects of FIN. It is likely that changes in neurosteroids may be primarily responsible for these effects; indeed, several clinical trials have shown that AP levels are reduced in the CSF and plasma of depressed individuals [75] and animal models of chronic stress [76]. Furthermore, AP exerts anxiolytic and antidepressant properties in animal models and humans [77], and has been recently approved by FDA for the treatment of post-partum depression [78]. In addition to AP, however, other $3 \alpha, 5 \alpha$-reduced neuroactive steroids might participate in the behavioral complications induced by FIN, including the testosterone metabolites DHT and $3 \alpha$-diol, which have been shown to exert positive effects on stress coping and motivation $[8,9,79,80]$.

These limitations notwithstanding, the results of this study qualified the impact of FIN across a broad range of behavioral domains. Given the emerging evidence on the neuropsychiatric complications of FIN and its therapeutic potential in Tourette's syndrome and pathological gambling, our findings may be critical for the understanding of the neurobehavioral mechanisms underpinning these outcomes and the development of novel steroid-based treatments that may preserve the therapeutic effects of FIN while reducing its liability for adverse events.

Author Contributions: L.J.M., S.C.G., G.F., and R.C. performed behavioral tests, monitored data collection, analyzed behavioral data. D.P.J. designed the experiments of delay discounting and discussed the paper. C.J.K., A.A.W., and C.A.F. performed gonadectomy experiments and analyzed behavioral data. Z.M. measured CRH and ACTH levels. N.A.M. designed the neurochemical experiments and supervised data analysis. S.S. wrote and edited the final version of manuscript. M.B. designed the experiments, supervised the experimental execution, monitored data collection, wrote and revised the manuscript.

Funding: The present manuscript was supported by the National Institute of Health grant R21 NS108722 and a grant from the Post-Finasteride Syndrome Foundation (to M.B.).

Acknowledgments: We are grateful to Gonzalo Carrasco, Hunter Strathman, Lyle Harte, Mason Mitchell, Claudia Collu, Eva Vigato, Karen Odeh, and Stefanos Louizou for their valuable assistance with the execution of the study.

Conflicts of Interest: The authors confirm that there are no known conflicts of interest associated with this publication and there has been no significant financial support for this work that could have influenced its outcome. 


\section{References}

1. Russell, D. Steroid 5-alpha Reductase: Two Genes/Two Enzymes. Annu. Rev. Biochem. 1994, 63, $25-61$. [CrossRef] [PubMed]

2. Paba, S.; Frau, R.C.; Godar, S.; Devoto, P.; Marrosu, F.; Bortolato, M. Steroid $5 \alpha$-Reductase as a Novel Therapeutic Target for Schizophrenia and Other Neuropsychiatric Disorders. Curr. Pharm. Des. 2011, 17, 151-167. [CrossRef] [PubMed]

3. Majewska, M.D. Neurosteroids: Endogenous bimodal modulators of the GABAA receptor mechanism of action and physiological significance. Prog. Neurobiol. 1992, 38, 379-395. [CrossRef]

4. Reddy, D.S.; Jian, K. The testosterone-derived neurosteroid androstanediol is a positive allosteric modulator of GABAA receptors. J. Pharmacol. Exp. Ther. 2010, 334, 1031-1041. [CrossRef] [PubMed]

5. Eser, D.; Schüle, C.; Baghai, T.C.; Romeo, E.; Rupprecht, R. Neuroactive steroids in depression and anxiety disorders: Clinical studies. Neuroendocrinology 2007, 84, 244-254. [CrossRef] [PubMed]

6. Schüle, C.; Baghai, T.; Laakmann, G. Mirtazapine Decreases Stimulatory Effects of Reboxetine on Cortisol, Adrenocorticotropin and Prolactin Secretion in Healthy Male Subjects. Neuroendocrinology 2004, 79, 54-62. [CrossRef]

7. Reddy, D.S. Is there a physiological role for the neurosteroid THDOC in stress-sensitive conditions? Trends Pharmacol. Sci. 2003, 24, 103-106. [CrossRef]

8. Frye, C.A.; Duncan, J.E.; Basham, M.; Erskine, M.S. Behavioral effects of 3a-androstanediol II: Hypothalamic and preoptic area actions via a GABAergic mechanism. Behav. Brain Res. 1996, 79, 119-130. [CrossRef]

9. Frye, C.A.; Van Keuren, K.R.; Erskine, M.S. Behavioral effects of $3 \alpha$-androstanediol I: Modulation of sexual receptivity and promotion of GABA-stimulated chloride flux. Behav. Brain Res. 1996, 79, 109-118. [CrossRef]

10. McInnes, K.J.; Kenyon, C.J.; Chapman, K.E.; Livingstone, D.E.W.; Macdonald, L.J.; Walker, B.R.; Andrew, R. $5 \alpha$-reduced glucocorticoids, novel endogenous activators of the glucocorticoid receptor. J. Biol. Chem. 2004, 279, 22908-22912. [CrossRef]

11. Uygur, M.C.; Arik, A.I.; Altuğ, U.; Erol, D. Effects of the 5 alpha-reductase inhibitor finasteride on serum levels of gonadal, adrenal, and hypophyseal hormones and its clinical significance: A prospective clinical study. Steroids 1998, 63, 208-213. [CrossRef]

12. Drake, L.; Hordinsky, M.; Fiedler, V.; Swinehart, J.; Unger, W.P.; Cotterill, P.C.; Thiboutot, D.M.; Lowe, N.; Jacobson, C.; Whiting, D.; et al. The effects of finasteride on scalp skin and serum androgen levels in men with androgenetic alopecia. J. Am. Acad. Dermatol. 1999, 41, 550-554. [PubMed]

13. Mukai, Y.; Higashi, T.; Nagura, Y.; Shimada, K. Studies on neurosteroids XXV. Influence of a $5 \alpha$-reductase inhibitor, finasteride, on rat brain neurosteroid levels and metabolism. Biol. Pharm. Bull. 2008, 31, 1646-1650. [CrossRef] [PubMed]

14. Concas, A.; Mostallino, M.C.; Porcu, P.; Follesa, P.; Barbaccia, M.L.; Trabucchi, M.; Purdy, R.H.; Grisenti, P.; Biggio, G. Role of brain allopregnanolone in the plasticity of $\gamma$-aminobutyric acid type A receptor in rat brain during pregnancy and after delivery. Proc. Natl. Acad. Sci. USA 1998, 95, 13284-13289. [CrossRef]

15. Dusková, M.; Hill, M.; Hanus, M.; Matousková, M.; Stárka, L. Finasteride treatment and neuroactive steroid formation. Prague Med. Rep. 2009, 110, 222-230.

16. Altomare, G.; Capella, G.L. Depression Circumstantially Related to the Administration of Finasteride for Androgenetic Alopecia. J. Dermatol. 2002, 29, 665-669. [CrossRef]

17. Rahimi-Ardabili, B.; Pourandarjani, R.; Habibollahi, P.; Mualeki, A. Finasteride induced depression: A prospective study. BMC Clin. Pharmacol. 2006, 6, 7. [CrossRef]

18. Traish, A.M.; Melcangi, R.C.; Bortolato, M.; Garcia-Segura, L.M.; Zitzmann, M. Adverse effects of $5 \alpha$-reductase inhibitors: What do we know, don't know, and need to know? Rev. Endocr. Metab. Disord. 2015, 16, 177-198. [CrossRef]

19. Irwig, M.S. Depressive Symptoms and Suicidal Thoughts Among Former Users of Finasteride with Persistent Sexual Side Effects. J. Clin. Psychiatry 2012, 73, 1220-1223. [CrossRef]

20. Melcangi, R.C.; Caruso, D.; Abbiati, F.; Giatti, S.; Calabrese, D.; Piazza, F.; Cavaletti, G. Neuroactive Steroid Levels are Modified in Cerebrospinal Fluid and Plasma of Post-Finasteride Patients Showing Persistent Sexual Side Effects and Anxious/Depressive Symptomatology. J. Sex. Med. 2013, 10, 2598-2603. [CrossRef]

21. Ganzer, C.A.; Jacobs, A.R.; Iqbal, F. Persistent Sexual, Emotional, and Cognitive Impairment Post-Finasteride. Am. J. Mens. Health 2015, 9, 222-228. [CrossRef] [PubMed] 
22. Ganzer, C.A.; Jacobs, A.R. Emotional Consequences of Finasteride: Fool's Gold. Am. J. Mens. Health 2018, 12, 90-95. [CrossRef] [PubMed]

23. Gray, S.L.; Semla, T.P. Post-finasteride syndrome. BMJ 2019, 366, 15047. [CrossRef] [PubMed]

24. Muroni, A.; Paba, S.; Puligheddu, M.; Marrosu, F.; Bortolato, M. A preliminary study of finasteride in Tourette syndrome. Mov. Disord. 2011, 26, 2146-2147. [CrossRef]

25. Bortolato, M.; Cannas, A.; Solla, P.; Bini, V.; Puligheddu, M.; Marrosu, F. Finasteride Attenuates Pathological Gambling in Patients With Parkinson Disease. J. Clin. Psychopharmacol. 2012, 32, 424-425. [CrossRef]

26. Devoto, P.; Frau, R.; Bini, V.; Pillolla, G.; Saba, P.; Flore, G.; Corona, M.; Marrosu, F.; Bortolato, M. Inhibition of $5 \alpha$-reductase in the nucleus accumbens counters sensorimotor gating deficits induced by dopaminergic activation. Psychoneuroendocrinology 2012, 37, 1630-1645. [CrossRef]

27. Pes, R.; Godar, S.C.; Fox, A.T.; Burgeno, L.M.; Strathman, H.J.; Jarmolowicz, D.P.; Devoto, P.; Levant, B.; Phillips, P.E.; Fowler, S.C.; et al. Pramipexole enhances disadvantageous decision-making: Lack of relation to changes in phasic dopamine release. Neuropharmacology 2017, 114, 77-87. [CrossRef]

28. Bortolato, M.; Campolongo, P.; Mangieri, R.A.; Scattoni, M.L.; Frau, R.; Trezza, V.; La Rana, G.; Russo, R.; Calignano, A.; Gessa, G.L.; et al. Anxiolytic-Like Properties of the Anandamide Transport Inhibitor AM404. Neuropsychopharmacology 2006, 31, 2652-2659. [CrossRef]

29. Tanda, G.; Di Chiara, G. A dopamine- $\mu 1$ opioid link in the rat ventral tegmentum shared by palatable food (Fonzies) and non-psychostimulant drugs of abuse. Eur. J. Neurosci. 1998, 10, 1179-1187. [CrossRef]

30. Bortolato, M.; Bini, V.; Frau, R.; Devoto, P.; Pardu, A.; Fan, Y.; Solbrig, M.V. Juvenile cannabinoid treatment induces frontostriatal gliogenesis in Lewis rats. Eur. Neuropsychopharmacol. 2014, 24, 974-985. [CrossRef]

31. Evenden, J.L.; Ryan, C.N. The pharmacology of impulsive behaviour in rats: The effects of drugs on response choice with varying delays of reinforcement. Psychopharmacology. 1996, 128, 161-170. [CrossRef] [PubMed]

32. Frau, R.; Bini, V.; Soggiu, A.; Scheggi, S.; Pardu, A.; Fanni, S.; Roncada, P.; Puligheddu, M.; Marrosu, F.; Caruso, D.; et al. The Neurosteroidogenic Enzyme $5 \alpha$-Reductase Mediates Psychotic-Like Complications of Sleep Deprivation. Neuropsychopharmacology 2017, 42, 2196-2205. [CrossRef] [PubMed]

33. Gobbi, G.; Bambico, F.R.; Mangieri, R.; Bortolato, M.; Campolongo, P.; Solinas, M.; Cassano, T.; Morgese, M.G.; Debonnel, G.; Duranti, A.; et al. Antidepressant-like activity and modulation of brain monoaminergic transmission by blockade of anandamide hydrolysis. Proc. Natl. Acad. Sci. USA 2005, 102, 18620-18625. [CrossRef] [PubMed]

34. Li, Q.; Muma, N.A.; Battaglia, G.; Van de Kar, L.D. A desensitization of hypothalamic 5-HT1A receptors by repeated injections of paroxetine: Reduction in the levels of $G(\mathrm{i})$ and $\mathrm{G}(\mathrm{o})$ proteins and neuroendocrine responses, but not in the density of 5-HT1A receptors. J. Pharmacol. Exp. Ther. 1997, 282, 1581-1590.

35. McAllister, C.E.; Mi, Z.; Mure, M.; Li, Q.; Muma, N.A. GPER1 Stimulation Alters Posttranslational Modification of RGSz1 and Induces Desensitization of 5-HT 1A Receptor Signaling in the Rat Hypothalamus. Neuroendocrinology 2014, 100, 228-239. [CrossRef]

36. Jiang, Y.-Q.; Kawashima, H.; Iwasaki, Y.; Uchida, K.; Sugimoto, K.; Itoi, K. Differential effects of forced swim-stress on the corticotropin-releasing hormone and vasopressin gene transcription in the parvocellular division of the paraventricular nucleus of rat hypothalamus. Neurosci. Lett. 2004, 358, 201-204. [CrossRef]

37. Jutkiewicz, E.M.; Wood, S.K.; Houshyar, H.; Hsin, L.W.; Rice, K.C.; Woods, J.H. The effects of CRF antagonists, antalarmin, CP154,526, LWH234, and R121919, in the forced swim test and on swim-induced increases in adrenocorticotropin in rats. Psychopharmacology 2005, 180, 215-223. [CrossRef] [PubMed]

38. Scheggi, S.; De Montis, M.G.; Gambarana, C. Making Sense of Rodent Models of Anhedonia. Int. J. Neuropsychopharmacol. 2018, 21, 1049-1065. [CrossRef]

39. Kalueff, A.V.; Aldridge, J.W.; LaPorte, J.L.; Murphy, D.L.; Tuohimaa, P. Analyzing grooming microstructure in neurobehavioral experiments. Nat. Protoc. 2007, 2, 2538-2544. [CrossRef]

40. Bortolato, M.; Muroni, A.; Marrosu, F. Treatment of Tourette's Syndrome with Finasteride. Am. J. Psychiatry 2007, 164, 1914-1915. [CrossRef]

41. Commons, K.G.; Cholanians, A.B.; Babb, J.A.; Ehlinger, D.G. The Rodent Forced Swim Test Measures Stress-Coping Strategy, Not Depression-like Behavior. ACS Chem. Neurosci. 2017, 8, 955-960. [CrossRef] [PubMed]

42. Overstreet, D.H. Modeling depression in animal models. Methods Mol. Biol. 2012, 829, 125-144. [PubMed] 
43. Walf, A.A.; Kaurejo, S.; Frye, C.A. Research Brief: Self-Reports of a Constellation of Persistent Antiandrogenic, Estrogenic, Physical, and Psychological Effects of Finasteride Usage Among Men. Am. J. Mens Health. 2018, 12, 900-906. [CrossRef]

44. Ciotta, L.; Cianci, A.; Calogero, A.E.; Palumbo, M.A.; Marletta, E.; Sciuto, A.; Palumbo, G. Clinical and endocrine effects of finasteride, a $5 \alpha$-reductase inhibitor, in women with idiopathic hirsutism. Fertil. Steril. 1995, 64, 299-306. [CrossRef]

45. Lakryc, E.M.; Motta, E.L.A.; Soares, J.M.; Haidar, M.A.; Rodrigues de Lima, G.; Baracat, E.C. The benefits of finasteride for hirsute women with polycystic ovary syndrome or idiopathic hirsutism. Gynecol. Endocrinol. 2003, 17, 57-63. [CrossRef] [PubMed]

46. Trüeb, R.M. Finasteride Treatment of Patterned Hair Loss in Normoandrogenic Postmenopausal Women. Dermatology 2004, 209, 202-207. [CrossRef]

47. Iorizzo, M.; Vincenzi, C.; Voudouris, S.; Piraccini, B.M.; Tosti, A. Finasteride Treatment of Female Pattern Hair Loss. Arch. Dermatol. 2006, 142, 298-302. [CrossRef]

48. Makhlouf, A.A.; Mohamed, M.A.; Seftel, A.D.; Niederberger, C. Hypogonadism is associated with overt depression symptoms in men with erectile dysfunction. Int. J. Impot. Res. 2008, 20, 157-161. [CrossRef]

49. Sarkar, J.; Wakefield, S.; MacKenzie, G.; Moss, S.J.; Maguire, J. Neurosteroidogenesis is required for the physiological response to stress: Role of neurosteroid-sensitive GABAA receptors. J. Neurosci. 2011, 31, 18198-18210. [CrossRef]

50. Melón, L.C.; Maguire, J. GABAergic regulation of the HPA and HPG axes and the impact of stress on reproductive function. J. Steroid Biochem. Mol. Biol. 2016, 160, 196-203. [CrossRef]

51. Roy, B.N.; Reid, R.L.; Van Vugt, D.A. The effects of estrogen and progesterone on corticotropin-releasing hormone and arginine vasopressin messenger ribonucleic acid levels in the paraventricular nucleus and supraoptic nucleus of the rhesus monkey. Endocrinology. 1999, 140, 2191-2198. [CrossRef] [PubMed]

52. Dallman, M.F.; Yates, F.E. Dynamic asymmetries in the corticosteroid feedback path and distributionmetabolism-binding elements of the adrenocortical system. Ann. Acad. Sci. 1969, 156, 696-721. [CrossRef] [PubMed]

53. Gjerstad, J.K.; Lightman, S.L.; Spiga, F. Role of glucocorticoid negative feedback in the regulation of HPA axis pulsatility. Stress 2018, 21, 403-416. [CrossRef] [PubMed]

54. Herman, J.P.; Figueiredo, H.; Mueller, N.K.; Ulrich-Lai, Y.; Ostrander, M.M.; Choi, D.C.; Cullinan, W.E. Central mechanisms of stress integration: Hierarchical circuitry controlling hypothalamo-pituitary-adrenocortical responsiveness. Front. Neuroendocrinol. 2003, 24, 151-180. [CrossRef]

55. Bale, T.L.; Vale, W.W. CRF and CRF receptors: Role in Stress Responsivity and Other Behaviors. Annu. Rev. Pharmacol. Toxicol. 2004, 44, 525-557. [CrossRef]

56. García-Lecumberri, C.; Ambrosio, E. Role of corticotropin-releasing factor in forced swimming test. Eur. J. Pharmacol. 1998, 343, 17-26. [CrossRef]

57. Zebrowska-Łupina, I.; Pietrasiewicz, T.; Ossowska, G.; Łupina, T.; Klenk-Majewska, B. ACTH 4-9 analogue facilitates the antiimmobility effect of antidepressants and dopamine agonists in swimming rats. J. Physiol. Pharmacol. 1997, 48, 263-275.

58. Korte, S.M.; Bouws, G.A.; Bohus, B. Central actions of corticotropin-releasing hormone (CRH) on behavioral, neuroendocrine, and cardiovascular regulation: Brain corticoid receptor involvement. Horm Behav. 1993, 27 , 167-183. [CrossRef]

59. Shibasaki, T.; Yamauchi, N.; Hotta, M.; Imaki, T.; Oda, T.; Ling, N.; Demura, H. Brain corticotropin-releasing hormone increases arousal in stress. Brain Res. 1991, 554, 352-354. [CrossRef]

60. Dunn, A.J.; Berridge, C.W. Physiological and behavioral responses to corticotropin-releasing factor administration: Is CRF a mediator of anxiety or stress responses? Brain Res. Rev. 1990, 15, 71-100. [CrossRef]

61. Bortolato, M.; Frau, R.; Orru, M.; Bourov, Y.; Marrosu, F.; Mereu, G.; Devoto, P.; Gessa, G.L. Antipsychotic-like properties of 5-alpha-reductase inhibitors. Neuropsychopharmacology 2008, 33, 3146-3156. [CrossRef] [PubMed]

62. Frau, R.; Mosher, L.J.; Bini, V.; Pillolla, G.; Pes, R.; Saba, P.; Fanni, S.; Devoto, P.; Bortolato, M. The neurosteroidogenic enzyme $5 \alpha$-reductase modulates the role of $\mathrm{D} 1$ dopamine receptors in rat sensorimotor gating. Psychoneuroendocrinology 2016, 63, 59-67. [CrossRef] [PubMed]

63. Soggiu, A.; Piras, C.; Greco, V.; Devoto, P.; Urbani, A.; Calzetta, L.; Bortolato, M.; Roncada, P. Exploring the neural mechanisms of finasteride: A proteomic analysis in the nucleus accumbens. Psychoneuroendocrinology 2016, 74, 387-396. [CrossRef] [PubMed] 
64. Feenstra, M.G.; Botterblom, M.H.; van Uum, J.F. Behavioral arousal and increased dopamine efflux after blockade of NMDA-receptors in the prefrontal cortex are dependent on activation of glutamatergic neurotransmission. Neuropharmacology 2002, 42, 752-763. [CrossRef]

65. Horvitz, J.C. Mesolimbocortical and nigrostriatal dopamine responses to salient non-reward events. Neuroscience. 2000, 96, 651-656. [CrossRef]

66. Sasibhushana, R.B.; Shankaranarayana Rao, B.S.; Srikumar, B.N. Repeated finasteride administration induces depression-like behavior in adult male rats. Behav. Brain Res. 2019, 365, 185-189. [CrossRef] [PubMed]

67. Tian, G.; Mook, R.; Moss, M.L.; Frye, S.V. Mechanism of Time-Dependent Inhibition of 5.alpha.-Reductases by $\Delta 1-4$-Azasteroids: Toward Perfection of Rates of Time-Dependent Inhibition by Using Ligand-Binding Energies. Biochemistry 1995, 34, 13453-13459. [CrossRef]

68. Thigpen, A.E.; Russell, D.W. Four-amino acid segment in steroid 5 alpha-reductase 1 confers sensitivity to finasteride, a competitive inhibitor. J. Biol. Chem. 1992, 267, 8577-8583.

69. Eicheler, W.; Tuohimaa, P.; Vilja, P.; Adermann, K.; Forssmann, W.G.; Aumüller, G. Immunocytochemical localization of human 5 alpha-reductase 2 with polyclonal antibodies in androgen target and non-target human tissues. J. Histochem. Cytochem. 1994, 42, 667-675. [CrossRef]

70. Aumuller, G.; Eicheler, W.; Renneberg, H.; Adermann, K.; Vilja, P.; Forssmann, W.G. Immunocytochemical evidence for differential subcellular localization of 5 alpha-reductase isoenzymes in human tissues. Cells Tissues Organs 1996, 156, 241-252. [CrossRef]

71. Azzouni, F.; Godoy, A.; Li, Y.; Mohler, J. The 5 Alpha-Reductase Isozyme Family: A Review of Basic Biology and Their Role in Human Diseases. Adv. Urol. 2012, 2012, 1-18. [CrossRef] [PubMed]

72. Castelli, M.P.; Casti, A.; Casu, A.; Frau, R.; Bortolato, M.; Spiga, S.; Ennas, M.G. Regional distribution of $5 \alpha$-reductase type 2 in the adult rat brain: An immunohistochemical analysis. Psychoneuroendocrinology 2013, 38, 281-293. [CrossRef] [PubMed]

73. Bortolato, M.; Devoto, P.; Roncada, P.; Frau, R.; Flore, G.; Saba, P.; Pistritto, G.; Soggiu, A.; Pisanu, S.; Zappala, A.; et al. Isolation rearing-induced reduction of brain $5 \alpha$-reductase expression: Relevance to dopaminergic impairments. Neuropharmacology. 2011, 60, 1301-1308. [CrossRef] [PubMed]

74. Diviccaro, S.; Giatti, S.; Borgo, F.; Barcella, M.; Borghi, E.; Trejo, J.L.; Garcia-Segura, L.M.; Melcangi, R.C. Treatment of male rats with finasteride, an inhibitor of 5alpha-reductase enzyme, induces long-lasting effects on depressive-like behavior, hippocampal neurogenesis, neuroinflammation and gut microbiota composition. Psychoneuroendocrinology 2019, 99, 206-215. [CrossRef]

75. Uzunova, V.; Sheline, Y.; Davis, J.M.; Rasmusson, A.; Uzunov, D.P.; Costa, E.; Guidotti, A. Increase in the cerebrospinal fluid content of neurosteroids in patients with unipolar major depression who are receiving fluoxetine or fluvoxamine. Proc. Natl. Acad. Sci. USA 1998, 95, 3239-3244. [CrossRef]

76. Dong, E.; Matsumoto, K.; Uzunova, V.; Sugaya, I.; Takahata, H.; Nomura, H.; Watanabe, H.; Costa, E.; Guidotti, A. Brain 5 -dihydroprogesterone and allopregnanolone synthesis in a mouse model of protracted social isolation. Proc. Natl. Acad. Sci. USA 2001, 98, 2849-2854. [CrossRef]

77. Schüle, C.; Nothdurfter, C.; Rupprecht, R. The role of allopregnanolone in depression and anxiety. Prog. Neurobiol. 2014, 113, 79-87. [CrossRef]

78. Meltzer-Brody, S.; Colquhoun, H.; Riesenberg, R.; Epperson, C.N.; Deligiannidis, K.M.; Rubinow, D.R.; Li, H.; Sankoh, A.J.; Clemson, C.; Schacterle, A.; et al. Brexanolone injection in post-partum depression: Two multicentre, double-blind, randomised, placebo-controlled, phase 3 trials. Lancet 2018, 392, 1058-1070. [CrossRef]

79. Frye, C.A.; Walf, A.A. Depression-like behavior of aged male and female mice is ameliorated with administration of testosterone or its metabolites. Physiol. Behav. 2009, 97, 266-269. [CrossRef]

80. Frye, C.A.; Edinger, K.L.; Lephart, E.D.; Walf, A.A. 3alpha-androstanediol, but not testosterone, attenuates age-related decrements in cognitive, anxiety, and depressive behavior of male rats. Front. Aging Neurosci. 2010, 2, 15 .

(C) 2019 by the authors. Licensee MDPI, Basel, Switzerland. This article is an open access article distributed under the terms and conditions of the Creative Commons Attribution (CC BY) license (http://creativecommons.org/licenses/by/4.0/). 